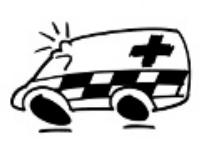

${ }^{1}$ Department of Anesthesiology and Critical Care Medicine, Innsbruck Medical University, Innsbruck, Austria;

${ }^{2}$ International Commission for Mountain Emergency Medicine, ICAR MEDCOM, Bruneck, Italy;

${ }^{3}$ Inova 0 Inc, Bruneck, Italy;

${ }^{4}$ Department of Anesthesiology and Critical Care Medicine,

General Hospital Bruneck,

Bruneck, Italy; ${ }^{5}$ Department of

Anesthesiology and Critical Care Medicine, Ludwig-Maximilians-

University Munich, Munich,

Germany; ${ }^{6}$ Mountain Rescue

Council England and Wales,

Pinfold, Penrith, Cumbria, UK

Correspondence to:

Dr P Paal, Department of

Anesthesiology and Critical Care

Medicine, Innsbruck Medical

University, Anichstrasse 35,

6020 Innsbruck, Austria; peter.

paal@i-med.ac.at

Accepted 2 September 2007

\title{
Retention of mouth-to-mouth, mouth-to-mask and mouth-to-face shield ventilation
}

\author{
P Paal, ${ }^{1,2}$ M Falk, ${ }^{3}$ E Gruber, ${ }^{4}$ W Beikircher, ${ }^{4}$ G Sumann, ${ }^{1,2} \mathrm{~F}$ Demetz, ${ }^{2,5}$ J Ellerton, ${ }^{2,6}$ \\ V Wenzel, ${ }^{1}$ H Brugger ${ }^{2}$
}

\section{ABSTRACT}

Background: Retention of mouth-to-mouth, mouth-tomask and mouth-to-face shield ventilation techniques is poorly understood.

Methods: A prospective randomised clinical trial was undertaken in January 2004 in 70 candidates randomly assigned to training in mouth-to-mouth, mouth-to-mask or mouth-to-face shield ventilation. Each candidate was trained for $10 \mathrm{~min}$, after which tidal volume, respiratory rate, minute volume, peak airway pressure and the presence or absence of stomach inflation were measured. 58 subjects were reassessed 1 year later and study parameters were recorded again. Data were analysed with ANOVA, $\chi^{2}$ and McNemar tests.

Results: Tidal volume, minute volume, peak airway pressure, ventilation rate and stomach inflation rate increased significantly at reassessment with all ventilation techniques compared with the initial assessment. However, at reassessment, mean (SD) tidal volume $(960$ (446) vs 1008 (366) vs 1402 (302) ml; $p<0.05$ ), minute volume (12 (5) vs 13 (7) vs 18 (3) l/min; $p<0.05)$, peak airway pressure (14 (8) vs 17 (13) vs 25 (8) $\mathrm{cm} \mathrm{H}_{2} \mathrm{O}$; $\mathrm{p}<0.05)$ and stomach inflation rate $(63 \%$ vs $58 \%$ vs $100 \% ; p<0.05)$ were significantly lower with mouth-tomask and mouth-to-face shield ventilation than with mouth-to-mouth ventilation. The ventilation rate at reassessment did not differ significantly between the ventilation techniques.

Conclusions: One year after a single episode of ventilation training, lay persons tended to hyperventilate; however, the degree of hyperventilation and resulting stomach inflation were lower when a mouth-to-mask or a face shield device was employed. Regular training is therefore required to retain ventilation skills; retention of skills may be better with ventilation devices.

Quality of basic life support in patients with cardiac arrest improves short-term survival, ${ }^{1}$ neurological outcome ${ }^{1}$ and hospital discharge rate. ${ }^{2}$ Great efforts are therefore being made to improve basic life support performance in lay persons. ${ }^{3}$ Unfortunately, lay persons are often reluctant to perform mouth-to-mouth ventilation because of concerns about acquiring infectious diseases. ${ }^{5}$ Moreover, the quality of artificial ventilation is often poor, with ventilation performance deteriorating further over time. ${ }^{6}$ Ventilation efforts in a patient with cardiac arrest may be impaired in two ways. First, hyperventilation may lead to stomach inflation-mediated pulmonary aspiration; ${ }^{7}$ moreover, excessive lung ventilation rates decrease coronary perfusion pressure during resuscitation efforts, impairing the outcome of cardiopulmonary resuscitation (CPR). ${ }^{8}$ Second, hypoventilation may lead to hypoxia and hypercarbia, two independent risk factors of a worse outcome for CPR. ${ }^{9}$

One possible strategy to make artificial ventilation more likely is to provide lay persons with mouth-to-mask or mouth-to-face shield ventilation devices in order to prevent direct mouth-to-mouth contact of the rescuer with the patient. ${ }^{10}$ In a recent study, after $10 \mathrm{~min}$ of ventilation training, mouth-to-mask and mouth-to-face shield ventilation produced a lower tidal volume, lower peak airway pressure and a lower incidence of stomach inflation than mouth-to-mouth ventilation. ${ }^{11}$ It is unknown whether this better performance with mouth-to-mask and mouth-to-face shield ventilation is retained 12 months later without further training.

The aim of this study was to compare mouth-tomouth, mouth-to-mask and mouth-to-face shield ventilation after a single episode of ventilation training (assessment) and 12 months later (reassessment) using an established bench model of an unprotected airway. ${ }^{11}$ Our null hypothesis was that there would be no difference in ventilation skills with mouth-to-mouth, mouth-to-mask and mouth-to-face shield ventilation immediately after a single ventilation training and 12 months later.

\section{METHODS}

The study was conducted in a high school in Bruneck, Italy, $840 \mathrm{~m}$ above sea level. The candidates were unpaid voluntary high school students who had attended an episode of ventilation training 12 months before, in January 2004. ${ }^{11}$ For that training, the candidates had been assigned randomly to one of three ventilation techniques: mouth-to-mouth, mouth-to-mask or mouth-toface shield ventilation. Each candidate was trained for $10 \mathrm{~min}$ in one of two teaching rooms by a physician experienced in CPR on a one-to-one basis and in accordance with the guidelines of the International Liaison Committee on Resuscitation (ILCOR). ${ }^{12}$ Theoretical and practical training was standardised using an instruction flow chart and a Laerdal Little Anne manikin. Candidates were instructed that ventilation was sufficient if the chest rose as recommended by the ILCOR guidelines. The assigned ventilation technique was explained and then demonstrated by the instructor. The candidates then performed ventilation without chest compressions under the guidance of the instructor. The results of the assessment immediately after the ventilation training in January 2004 have been reported previously. ${ }^{11}$

In January 2005 the same candidates were recalled and reassessed on the ventilation technique learnt 
12 months earlier. The results from January 2004 were termed "assessment" and those from January 2005 "reassessment". None of the candidates had attended a basic life support training in the meantime and candidates were not retrained before the reassessment. Each candidate gave written informed consent before participating in the study and underwent a health check consisting of a questionnaire, a physical examination (which included weight and height measurement) and spirometry. A previously described bench model of an unprotected airway was used. ${ }^{11}$ The head of the manikin was freely movable, so the candidates had to keep the upper airway open and ventilate the bench model. The tracheal outlet of the manikin was connected to a test lung (Bio Tek Ventilator Tester VT-2; Fluke Corporation, Everett, Washington, USA) and lung compliance was adjusted to $100 \mathrm{ml} / \mathrm{cm} \mathrm{H}_{2} \mathrm{O}$. The gastric outlet was connected to a pop-up valve simulating the lower oesophageal sphincter and the opening pressure was set to $14 \mathrm{~cm} \mathrm{H} \mathrm{H}_{2} \mathrm{O}$ as in the previous study. ${ }^{11}$ Air flow behind this artificial sphincter was measured with a flow sensor (Flowmeter TSI Certifier FA Mod 4078, Airflow Analyser Mod 4074; Shoreview, Minnesota, USA). Stomach inflation was considered to be present if the flow sensor was activated during the ventilation efforts of a candidate.

The candidates had to treat the bench model as an adult in respiratory arrest. Before the reassessment they were allowed to familiarise themselves with the bench model and to perform four practice ventilations. The candidates then continuously ventilated the bench model while the study parameters were recorded by the Bio Tek Ventilator tester. The Bio Tek Ventilator tester averages results after every four ventilations (ie, one ventilation series), and three ventilation series were measured consecutively. Candidates were blinded to all measurements but were able to observe the artificial chest rise and fall as in a clinical situation.

Primary outcome variables were tidal volume, minute volume, peak airway pressure, ventilation rate and the presence or absence of stomach inflation. To detect at least a difference of $10 \%$ in primary outcome variables with an $\alpha$ value of 0.05 and power of 0.8 , a sample size of 52 subjects was needed. Height and gender directly affect spirometric results so the continuous variables height and vital capacity were checked graphically and tested against normal distribution using the one-sample Kolmogorov-Smirnov test. For tidal volume, minute ventilation and peak airway pressure, ANOVA for repeated measures was used to test differences between techniques and differences in ventilation parameters between assessment in January 2004 and reassessment in January 2005 (termed Delta). To test for differences between assessment and reassessment in stomach inflation, the McNemar test was used. Differences between techniques were analysed with the $\chi^{2}$ test using the combined results from initial assessment and reassessment as a target variable. When ANOVA or the $\chi^{2}$ test indicated a significant treatment effect, a post hoc pairwise comparison with Bonferroni correction was employed. A p value of $<0.05$ was considered statistically significant, implying a $p$ value of $<0.05 /$ $3=0.016$ for the Bonferroni correction. SPSS 13 software (SPSS, Chicago, Illinois, USA) was used for statistical analysis. Data plots were generated using Matlab R14 SP3 (Mathwork Inc, Natick, Massachusetts, USA). Data are reported as mean (SD) or frequencies where appropriate.

The protocol of this prospective randomised clinical study was approved by the local ethics committee.

\section{RESULTS}

Fifty-eight of the 70 candidates (83\%) who had attended the 10 min ventilation training in January 2004 presented for reassessment 12 months later; 22 (38\%) were female and 36 $(62 \%)$ were male. All candidates were healthy and classified as ASA I according to the American Society of Anesthesiologists score. ${ }^{13}$ Biometric data of the candidates at assessment and reassessment are given in table 1 .

The continuous variables height, weight and vital capacity were normally distributed between the three ventilation groups in January 2004 and January 2005; no significant difference attributable to gender, weight, height and vital capacity was found for the investigated ventilation parameters.

Significant results of the assessment after the $10 \mathrm{~min}$ ventilation training, of the reassessment 12 months later, and the difference in ventilation parameters between assessment and reassessment (termed Delta) are shown in fig 1 and table 2, respectively. At reassessment, tidal volume, minute volume, peak airway pressure, ventilation rate and stomach inflation rate increased significantly (all $p<0.001$, table 2) with all ventilation techniques compared with the assessment. However, at reassessment, mean (SD) tidal volume (960 (446) vs 1008 (366) vs 1402 (302) ml; p<0.05), minute volume (12 (5) vs 13 (7) vs 18 (3) l/min; p<0.05), peak airway pressure (14 (8) vs $17(13)$ vs 25 (8) $\mathrm{cm} \mathrm{H}_{2} \mathrm{O}$; p <0.05) and stomach inflation rate $(63 \%$ vs $58 \%$ vs $100 \%$; $<<0.05)$ were significantly lower with mouth-to-mask and mouth-to-face shield than with mouth-tomouth ventilation.

At reassessment, tidal volume, minute volume, peak airway pressure, ventilation rate and stomach inflation rate increased significantly with all ventilation techniques compared with the assessment. Moreover, at reassessment, tidal volume, minute volume, peak airway pressure and stomach inflation rate were significantly lower with mouth-to-mask and mouth-to-face shield than with mouth-to-mouth ventilation.

Table 1 Mean (SD) biometric data of candidates at assessment and reassessment 12 months later

\begin{tabular}{llll}
\hline & $\begin{array}{l}\text { Mouth-to-mouth } \\
\text { ventilation }\end{array}$ & $\begin{array}{l}\text { Mouth-to-mask } \\
\text { ventilation }\end{array}$ & $\begin{array}{l}\text { Mouth-to-face } \\
\text { shield ventilation }\end{array}$ \\
\hline $\begin{array}{l}\text { Total (F/M) } \\
\text { Height (cm) }\end{array}$ & $20(6 / 14)$ & $19(6 / 13)$ & $19(9 / 10)$ \\
$\quad \begin{array}{l}\text { Assessment } \\
\text { Reassessment }\end{array}$ & $175(8)$ & $175(7)$ & $172(8)$ \\
Weight (kg) & $177(9)$ & $177(8)$ & $175(9)$ \\
$\quad$ Assessment & $67(11)$ & $65(10)$ & $61(8)$ \\
$\quad$ Reassessment & $69(12)$ & $67(10)$ & $62(8)$ \\
Vital capacity (m) & & & \\
$\quad$ Assessment & $4304(650)$ & $4569(897)$ & $3917(764)$ \\
Reassessment & $4486(814)$ & $4656(916)$ & $4218(760)$ \\
\hline
\end{tabular}


Figure 1 Mean values with standard deviation for tidal volume, minute volume, peak airway pressure and stomach inflation at assessment (after a single episode of ventilation training) and at reassessment 12 months later for mouthto-mouth, mouth-to-mask and mouth toface shield ventilation. ${ }^{*} p<0.05$, significant differences between ventilation techniques.
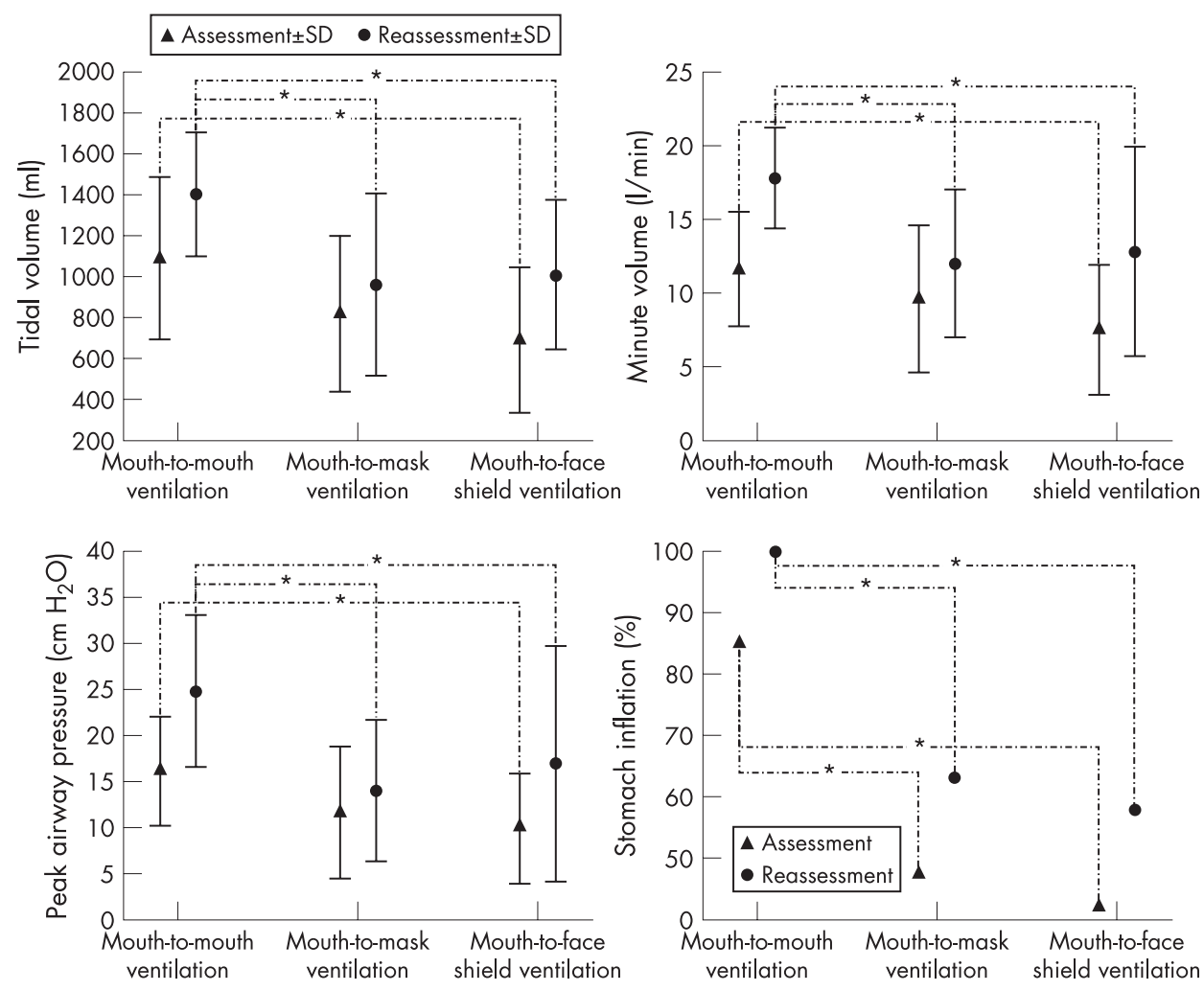

\section{DISCUSSION}

Mouth-to-mask and mouth-to-face shield ventilation resulted in lower tidal volume, minute volume, peak airway pressure and less stomach inflation than mouth-to-mouth ventilation, indicating that these devices with a built-in one-way valve or an antibacterial filter may slow down enthusiastic but inadvertent artificial ventilation by limiting peak flow and peak airway pressure. ${ }^{14}$ Mouth-to-mask and mouth-to-face shield

Table 2 Mean (SD) ventilation results at assessment and reassessment 12 months later

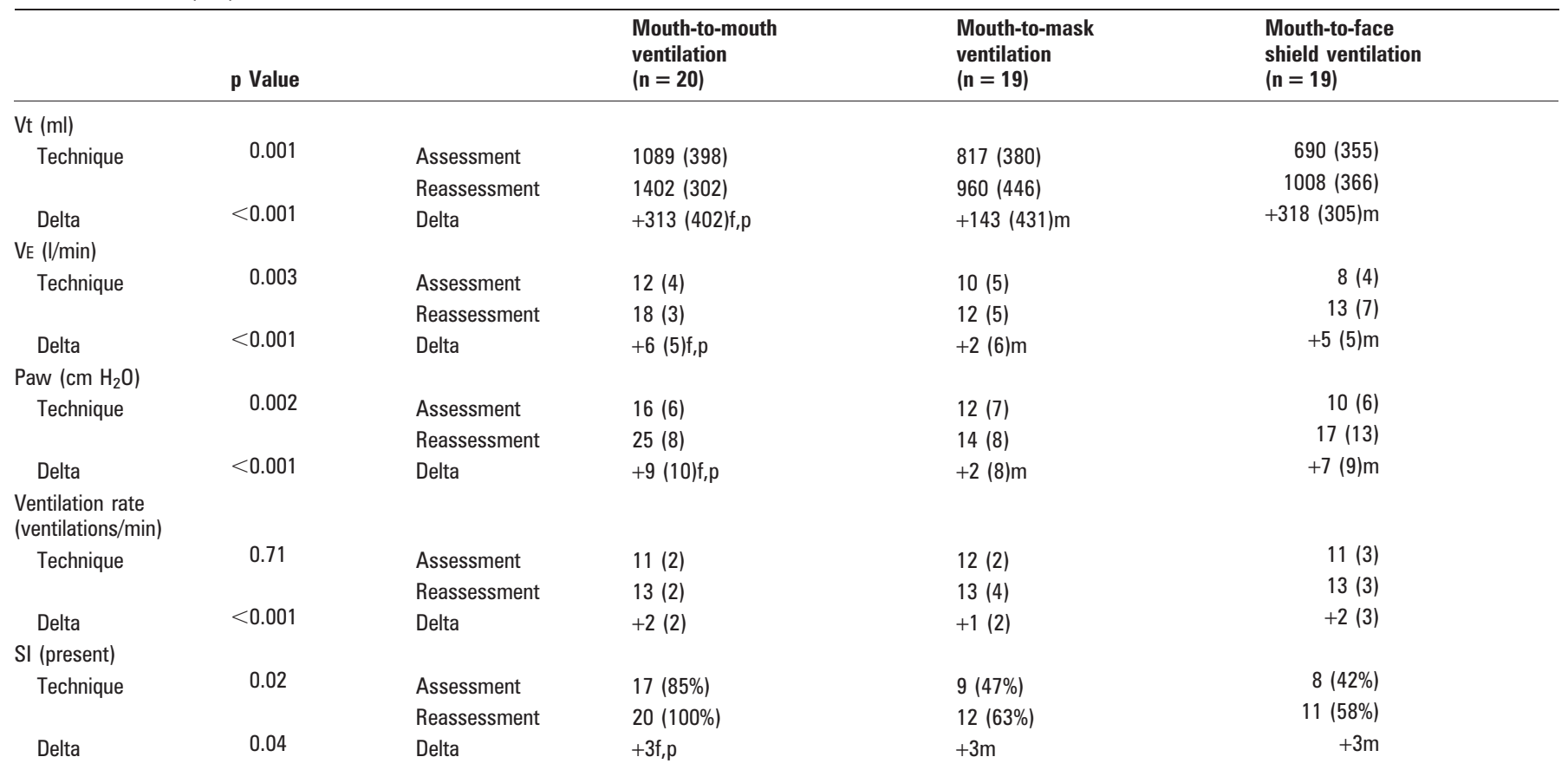

$\mathrm{Vt}$, tidal volume; $\mathrm{VE}_{\mathrm{E}}$ minute ventilation; Paw, peak airway pressure, $\mathrm{SI}$, stomach inflation.

Results at initial assessment in January 2004 (Assessment), reassessment in January 2005 (Reassessment) and difference between assessment and reassessment (Delta) are shown.

Stomach inflation (SI) is shown as a percentage of candidates causing stomach inflation.

Significant differences $(\mathrm{p}<0.016)$ in Delta between techniques are marked $(m)$ for comparisons with mouth-to-mouth, ( $f)$ for comparisons with mouth-to-face shield and $(p)$ for comparisons with mouth-to-mask ventilation. 
ventilation may therefore combine protection of the rescuer from infectious diseases ${ }^{15}$ and the patient from hyperventilation. Hyperventilation is detrimental in cardiac arrest because it causes stomach inflation and may lead to pulmonary aspiration; ${ }^{7}$ moreover, by increasing intrathoracic pressure, hyperventilation decreases venous return and therefore coronary perfusion pressure. $^{816}$ While absolute tidal volume, minute volume, peak airway pressure and stomach inflation rate increased with all ventilation techniques, significantly lower values with mouth-to-mask and mouth-to-face shield ventilation may indicate that built-in features in the devices were of value. Interestingly, the ventilation rate increased significantly between the assessment (11/min) and the reassessment (13/ $\mathrm{min}$ ) with the investigated ventilation techniques. The ILCOR guidelines suggest 10 ventilations $/ \mathrm{min} ;{ }^{10}$ an increase in ventilation rate may be detrimental for the CPR outcome. ${ }^{8}$

Ventilation of an unprotected airway is a complex psychomotor task. There are factors which depend on the rescuer, such as opening the upper airway, keeping it patent and ventilating the lungs sufficiently without inflating the stomach. ${ }^{17}{ }^{18}$ Other factors cannot be influenced by the rescuer and are inherent to a patient with cardiac arrest. These include increased airway resistance, decreased pulmonary compliance and decreased lower oesophageal sphincter pressure. ${ }^{19}$ It is therefore not surprising that ventilation of an unprotected airway during CPR by lay persons is associated with pulmonary aspiration of gastric contents in about $25 \%$ of cases. ${ }^{7}$ Problems with adequate artificial ventilation also occur in professional emergency medical services. For example, even experienced paramedics used excessive ventilation rates $(30 / \mathrm{min}$ instead of $10 / \mathrm{min})$ with a bag-valve mask device, ${ }^{8}$ and third year anaesthesia residents caused increased peak airway pressures resulting in stomach inflation when a bag-valve mask was used to ventilate patients during the routine induction of anaesthesia. ${ }^{20}$

In a recent hospital survey, $75 \%$ of respondents reported that they felt their training in CPR was not sufficient. ${ }^{21}$ CPR skills deteriorate over time, both in lay persons and in healthcare personnel..$^{22}$ There are several reasons for this including, among others, high stress levels during basic life support in a cardiac arrest situation and inappropriate time to practise during basic life support instruction, thus resulting in an inadequate acquisition of the initial skill. ${ }^{23}$ Ventilation skills are better acquired and retained when a manikin gives verbal feedback in an initial training, as well as in the retraining. ${ }^{24}$

This study has some limitations. First, we determined skill retention in an experimental setting only, and parameters may vary greatly in a real CPR scenario because of higher stress levels. Second, the candidates were adolescents and lung vital capacity increased between initial training and reassessment; this might have contributed to the observed increase in the end points of the study. Third, this study focused on ventilation only and the results may not apply when they are combined with chest compressions, ${ }^{25}$ so further studies should incorporate chest compressions in the study protocol and investigate optimal training intervals and ventilation devices. Fourth, the candidates knew that they were being reassessed which could lead to exaggerated ventilation efforts. However, this effect applied to both the assessment and the reassessment, thus levelling the results.

\section{CONCLUSION}

One year after a single episode of ventilation training, lay persons tended to hyperventilate; however, the degree of hyperventilation and resulting stomach inflation was lower when a mouth-to-mask or a face shield device was employed. Regular training is therefore required to retain ventilation skills; the retention of skills may be better with ventilation devices.

Acknowledgements: The authors thank Alfred Niederhofer, head of the Bruneck "Realgymnasium" High School, and all participating candidates, and are indebted to Michael de Zordo, Andreas Neurauter and the members of the Mountain Rescue Service provided by the South Tyrolean Alpine Association for their enthusiastic technical and logistic support.

Funding: Mouth-to-mask and mouth-to-face shield ventilation devices used in this study were provided by Laerdal, Stavanger, Norway.

Competing interests: None.

\section{REFERENCES}

1. Van Hoeyweghen RJ, Bossaert LL, Mullie A, et al. Quality and efficiency of bystander CPR. Belgian Cerebral Resuscitation Study Group. Resuscitation 1993;26:47-52

2. Wik L, Steen PA, Bircher NG. Quality of bystander cardiopulmonary resuscitation influences outcome after prehospital cardiac arrest. Resuscitation 1994;28:195-203.

3. Eisenburger $\mathbf{P}$, Safar $\mathbf{P}$. Life supporting first aid training of the public: review and recommendations. Resuscitation 1999;41:3-18.

4. Heward A, Donohoe RT, Whitbread M. Retrospective study into the delivery of telephone cardiopulmonary resuscitation to "999" callers. Emerg Med J 2004;21:233-4.

5. Locke CJ, Berg RA, Sanders AB, et al. Bystander cardiopulmonary resuscitation. Concerns about mouth-to-mouth contact. Arch Intern Med 1995;155:938-43.

6. Smith A, Colquhoun M, Woollard M, et al. Trials of teaching methods in basic life support (4): Comparison of simulated CPR performance at unannounced home testing after conventional or staged training. Resuscitation 2004;61:41-7.

7. Virkkunen I, Kujala S, Ryynanen S, et al. Bystander mouth-to-mouth ventilation and regurgitation during cardiopulmonary resuscitation. J Intern Med 2006;260:39-42.

8. Aufderheide TP, Sigurdsson G, Pirrallo RG, et al. Hyperventilation-induced hypotension during cardiopulmonary resuscitation. Circulation 2004;109:1960-5.

9. Idris $\mathbf{A H}$, Wenzel V, Becker $L B$, et al. Does hypoxia or hypercarbia independently affect resuscitation from cardiac arrest? Chest 1995;108:522-8.

10. Handley AJ, Koster R, Monsieurs K, et al. European Resuscitation Council guidelines for resuscitation 2005, Section 2. Adult basic life support and use of automated external defibrillators. Resuscitation 2005;67(Suppl 1):S7-23.

11. Paal P, Falk M, Sumann G, et al. Comparison of mouth-to-mouth, mouth-to-mask and mouth-to-face-shield ventilation by lay persons. Resuscitation 2006;70:117-23.

12. Anon. Part 3: Adult basic life support. Resuscitation 2000;36:42-6.

13. American Society of Anesthesiologists. New classification of physical status. Anesthesiology 1963;24:111.

14. Hess D, Simmons M, Slikkers F, et al. Resistance to flow through the valves of mouth-to-mask ventilation devices. Respir Care 1993;38:183-8.

15. Cydulka RK, Connor PJ, Myers TF, et al. Prevention of oral bacterial flora transmission by using mouth-to-mask ventilation during CPR. J Emerg Med 1991; 9:317-21.

16. O'Neill JF, Deakin CD. Do we hyperventilate cardiac arrest patients? Resuscitation 2007;73:82-5.

17. Wenzel V, Idris AH, Dorges $V$, et al. The respiratory system during resuscitation: a review of the history, risk of infection during assisted ventilation, respiratory mechanics, and ventilation strategies for patients with an unprotected airway. Resuscitation 2001;49:123-34.

18. Dorges V, Ocker H, Wenzel V, et al. Emergency airway management by nonanaesthesia house officers: a comparison of three strategies. Emerg Med J 2001;18:90-4.

19. Gabrielli A, Wenzel V, Layon AJ, et al. Lower esophageal sphincter pressure measurement during cardiac arrest in humans: potential implications for ventilation of the unprotected airway. Anesthesiology 2005;103:897-9.

20. Wagner-Berger HG, Wenzel V, Voelckel WG, et al. A pilot study to evaluate the SMART BAG: a new pressure-responsive, gas-flow limiting bag-valve-mask device. Anesth Analg 2003;97:1686-9.

21. Skrifvars MB, Castren M, Kurola J, et al. In-hospital cardiopulmonary resuscitation: organization, management and training in hospitals of different levels of care. Acta Anaesthesiol Scand 2002;46:458-63.

22. Kaye W, Mancini ME. Retention of cardiopulmonary resuscitation skills by physicians, registered nurses, and the general public. Crit Care Med 1986;14:620-2.

23. Kaye W, Rallis SF, Mancini ME, et al. The problem of poor retention of cardiopulmonary resuscitation skills may lie with the instructor, not the learner or the curriculum. Resuscitation 1991;21:67-87.

24. Wik L, Myklebust H, Auestad BH, et al. Twelve-month retention of CPR skills with automatic correcting verbal feedback. Resuscitation 2005;66:27-30.

25. Rittenberger JC, Guimond G, Platt TE, et al. Quality of BLS decreases with increasing resuscitation complexity. Resuscitation 2006;68:365-9. 


\section{EM]}

\section{Retention of mouth-to-mouth, mouth-to-mask and mouth-to-face shield ventilation}

P Paal, M Falk, E Gruber, et al.

Emerg Med J 2008 25: 42-45

doi: 10.1136/emj.2007.050229

Updated information and services can be found at:

http://emj.bmj.com/content/25/1/42.full.html

These include:

References This article cites 25 articles, 4 of which can be accessed free at: http://emj.bmj.com/content/25/1/42.full.html\#ref-list-1

Article cited in:

http://emj.bmj.com/content/25/1/42.full.html\#related-urls

Email alerting service

Receive free email alerts when new articles cite this article. Sign up in the box at the top right corner of the online article.

Topic Articles on similar topics can be found in the following collections Collections

Notes

To request permissions go to:

http://group.bmj.com/group/rights-licensing/permissions

To order reprints go to:

http://journals.bmj.com/cgi/reprintform

To subscribe to BMJ go to:

http://group.bmj.com/subscribe/ 